\title{
HLA-B60 and HLA-DR4 alleles in Javanese children with steroid-sensitive primary nephrotic syndrome
}

\author{
MP Damanik
}

\begin{abstract}
Background Steroid-sensitive nephrotic syndrome (SSNS) of children is associated with several human leucocyte antigen (HLA) class I and class II.

Objective To investigate the association between HLA-B60 and HLA-DR4 alleles and primary nephrotic syndrome (PNS) in Javanese children.

Methods A case control study was conducted on 47 Javanese children with PNS who were typed for HLA-B60 and HLA-DR4 alleles, using DNA sequence specific oligonucleotide probe (SSOP) as control sample, 47 healthy children were also typed for those HLA antigens using the same technique.

Results Compared with control group, children with PNS had higher frequency of both HLA-B60 (23.32\% vs 4.3\%; OR=6.85 [Cl=1.3235.65]; $\mathrm{P}<0.01)$ and HLA-DR4 (40.0\% vs 2.1\%; OR=30.67 [Cl:3.71253.33]; $P<0.0002)$. There was association between HLA and PNS with SSNS in children.

Conclusion The strong association between PNS and HLA antigen support the immunogenetic background of the disease, which seems to be stronger in young children with SSNS. [Paediatr Indones 2006;46:246-249].
\end{abstract}

Keywords: steroid-sensitive nephrotic syndrome-

HLA type B60-DR4, case-control study

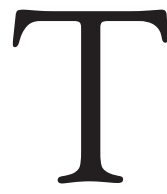

The etiology of steroid-sensitive nephrotic syndrome (SSNS) in childhood remains unknown. Several observations suggested an immunological mechanism for the disease. ${ }^{1}$ Some diseases with immunological bases are known to be associated with human leukocyte antigen (HLA) system. ${ }^{2}$ Several studies showed the evidence of increased frequencies of certain serologically typed HLA class II antigens in children with SSNS. ${ }^{3}$ One of the most important genetic elements that control an individual's immune response to foreign antigens resides within the HLA loci on chromosome 6. HLA associations have been extensively studied in various populations with SSNS. A close association has been found between SSNS in Caucasians and HLA-DR, especially DR7, 4,5 and the combined occurrence of HLA DR3 and DR7. ${ }^{6}$ HLA-DR7 is associated with a more severe clinical course. ${ }^{7}$ A previous study in a smaller group of Southern Chinese children with SSNS showed a positive association with HLA-DR7. ${ }^{8} \mathrm{~A}$ weaker association with HLA DR9 was seen in those children with frequent relapses. This study was aimed to investigate the association between both HLA class I (HLA-B60) and class II (HLADR4) gene polymorphisms, and SSNS in Indonesian children.

\section{Methods}

Subjects were new patients diagnosed as primary nephrotic syndrome (PNS), with no history of steroid

From the Department of Child Health, Medical School, Gajah Mada University, Yogyakarta, Indonesia.

Reprint request to: MP Damanik, MD, Division of Pediatric Nephrology, Department of Child Health, Medical School, Gadjah Mada University, Jl. Kesehatan No. 1, Sekip Utara, Yogyakarta 55281, Indonesia. Tel. 62 274-587333 Ext.232. Fax.62-274-583745. Email: parlin_d@yahoo.com. 
or immunosuppresive treatment, treated at the Pediatrics Ward of Sardjito Hospital, Yogyakarta from January 2000 to December 2002. Controls were healthy children attended the outpatient pediatric clinics in Sardjito Hospital, that already been confirmed not suffered from PNS based on normal routine urinalysis. They did not have bloodrelationship with cases and were macthed by sex, age and etnicity.

Diagnostic criteria of PNS in this study was based on the criteria used by the Collaborative Study of Childhood Renal Disorder in Indonesia (1989), and modified according to the International Study of Kidney Disease on Children (ISKDC), 1978.

During treatment with steroid (prednisone) for 8 weeks, clinical and laboratory follow-up were conducted to monitor treatment responses. Prednisone doses were based on ISKDC (1978). The first 4 weeks of treatment: $60 \mathrm{mg} / \mathrm{m}^{2} /$ day or $2 \mathrm{mg} / \mathrm{kg}$ body weight/day (maximum of $80 \mathrm{mg} / \mathrm{m}^{2} /$ day) in three doses, and the remaining 4 weeks: $40 \mathrm{mg} / \mathrm{m}^{2} / 48$ hours given at alternating doses every other day in the morning after meal. Based on the treatment results, patients were categorized into 2 groups, the steroid resistant and steroid sensitive groups. The criteria for steroid sensitive was complete remission with no edema, and negative proteinuria on routine urinalysis for three consecutive days in a week achieved after 8 weeks of steroid therapy. The criteria for steroid resistant was no remission after eight weeks of treatment.

HLA typing for both class I and II alleles gene loci were performed using the polymerase chain reaction-sequence spesific oligonucleotide probe (PCR-SSOP) methods, according to the protocol and primers from the $12^{\text {th }}$ International Histocompatibility Workshop. The WHO-HLA nomenclature was used for allele assignment. Blood samples were obtained from all studied subjects. The amount of $5 \mathrm{cc}$ blood was obtained from each subject using the heparin venoject (evaluated collecting tubes) and stored in the refrigerator of $5^{\circ} \mathrm{C}$ for HLA examination. The HLA examination was performed in ICMR, Kobe University, Medical School, Kobe, Japan.

The association between HLA phenotype and PNS in children was expressed as odds ratio, and calculated based on $2 \times 2$ table (bivariant analysis) as follow:

\begin{tabular}{|c|c|c|c|c|}
\hline & & Cases (PNS) & Controls (Healthy) & Total \\
\hline HLA/Risk & + & a & b & $a+b$ \\
\hline Factors & - & $\mathrm{C}$ & $d$ & $c+d$ \\
\hline Total & & $a+b$ & $b+d$ & $a+b+c+d$ \\
\hline
\end{tabular}

a-Proportion of primary nephrotic cases with positive HLA b-Proportion of healthy subject with positive HLA c-Proportion of primary nephrotic cases with negative HLA d-Proportion of healthy subject with negative HLA

Odds ratio (OR) calculated in this study is the estimated probability of a child to develop PNS or other disorders when she or he has specific HLA as the risk factor. The value of $\mathrm{OR}$ is calculated along with its confidence interval (CI) at $95 \%$. OR with CI $=1$ means that HLA is not a risk factor to diseases (HLA is a protective factor). While $\mathrm{OR}$ with $\mathrm{CI}>1$ means that the HLA is a risk factor. To calculate chi square with its P-value, data was analyzed using computer software SPSS PC version 3.2 and Epi Info version 3.0.

Due to technical limitation, the SSOP examinations were conducted only among 47 cases out of 120 patients with PNS, and on 47 healthy children. To control the confounding factors, cases and controls were matched by age and sex, and the same number of 47 cases and 47 controls were selected to achieve the minimum sample size. HLA analysis were conducted for both study groups using the same technique.

\section{Results}

In three years period, 120 new patients with PNS were recruited in the study. The patients were 74 boys $(61.7 \%)$ and 46 girls (38.3\%) with sex ratio of $1.5: 1$. The evaluation of treatment responses after eight weeks showed that $74.2 \%$ cases were steroid sensitive, and $25.4 \%$ were steroid resistant.

There was a significant association between HLA-B60 allele and HLA-DR4 with PNS (HLA-B60 $\mathrm{OR}=8.60 ; 95 \% \mathrm{CI}=1.82-40.69 ; \mathrm{P}<0.05$ as shown in Table 1, and HLA-DR4 OR=31.21; 95\%CI=3.96246.14; $\mathrm{P}<0.05$ as shown in Table 2 ). 
Table 1. Frequency of HLA-B allele in PNS patients and controls

\begin{tabular}{|c|c|c|c|c|c|c|}
\hline \multirow[t]{2}{*}{ Allele } & \multicolumn{2}{|c|}{ Cases } & \multicolumn{2}{|c|}{ Controls } & \multirow[t]{2}{*}{ OR $(95 \% \mathrm{Cl})$} & \multirow[t]{2}{*}{$\mathbf{P}$} \\
\hline & n (47) & $\%$ & n (47) & $\%$ & & \\
\hline B7 & - & - & 1 & 2.1 & - & 0.500 \\
\hline B13 & - & - & 2 & 4.3 & - & 0.247 \\
\hline B15 & 8 & 17.0 & 10 & 21.3 & $0.759(0.270-2.132)$ & 0.397 \\
\hline B18 & 20 & 42.6 & 11 & 23.4 & $2.424(0.997-5.897)$ & 0.039 \\
\hline B27 & 1 & 2.1 & 1 & 2.1 & $1.00(0.061-16.474)$ & 0.753 \\
\hline B33 & 1 & 2.1 & - & - & - & 0.500 \\
\hline B35 & 10 & 21.3 & 20 & 42.6 & $0.365(0.147-0.904)$ & 0.023 \\
\hline B38 & 3 & 6.4 & 2 & 4.3 & $1.534(0.244-9.629)$ & 0.500 \\
\hline B39 & 1 & 2.1 & 1 & 2.1 & $1.00(0.061-16.474)$ & 0.753 \\
\hline B40 & 2 & 4.3 & 1 & 2.1 & $2.044(0.179-23,348)$ & 0.500 \\
\hline B44 & 5 & 10.6 & 5 & 10.6 & $1.00(0.269-3.711)$ & 1.630 \\
\hline B45 & 1 & 2.1 & - & - & - & 0.500 \\
\hline B48 & 1 & 2.1 & 1 & 2.1 & $1.00(0.061-16.474)$ & 0.753 \\
\hline B51 & 10 & 21.3 & 10 & 21.3 & $1.00(0.372-2.686)$ & 0.599 \\
\hline B52 & 5 & 10.6 & 5 & 10.6 & $1.00(0.269-3.711)$ & 0.630 \\
\hline B53 & 6 & 12.8 & 3 & 6.4 & $2.146(0.504-9.148)$ & 0.243 \\
\hline B56 & 1 & 2.1 & 3 & 6.4 & 0.319 (0.032-3.182) & 0.308 \\
\hline B57 & 4 & 8.5 & 3 & 6.4 & $1.364(0.288-6.459)$ & 0.500 \\
\hline B58 & 3 & 6.4 & 3 & 6.4 & $1.00(0.191-5.228)$ & 1.661 \\
\hline $\mathrm{B} 60$ & 13 & 27.7 & 2 & 4.3 & 8.603(1.819-40.691) & 0.002 \\
\hline $\mathrm{B} 61$ & - & - & 1 & 2.1 & - & 0.500 \\
\hline B62 & 11 & 23.4 & 13 & 27.7 & $0.799(0.315-2.025)$ & 0.407 \\
\hline B72 & - & - & 1 & 2.1 & - & 0.500 \\
\hline B74 & 1 & 2.1 & - & - & - & 0.500 \\
\hline B75 & 17 & 36.2 & 21 & 44.7 & $0.702(0.307-1.605)$ & 0.264 \\
\hline B77 & 7 & 14.7 & 14 & 29.8 & $0.413(0.149-1.141)$ & 0.068 \\
\hline B78 & - & - & 2 & 4.3 & - & 0.243 \\
\hline
\end{tabular}

Table 2. Frequency of HLA-DR4 allele in PNS patients and controls

\begin{tabular}{lcccccc}
\hline Allele & \multicolumn{2}{c}{ Cases } & \multicolumn{2}{c}{ Control } & OR (95\%Cl) & P \\
& $\mathbf{n}(\mathbf{4 7})$ & $\%$ & $\mathbf{n}(\mathbf{4 7})$ & $\%$ & & \\
DR1 & 4 & 8.5 & 2 & 4.3 & $2.093(0.364-12.021)$ & 0.339 \\
DR3 & 2 & 4.3 & - & - & - & 0.217 \\
DR4 & 19 & 40.4 & 1 & 2.1 & $31.214(3.958-246.141)$ & 0.005 \\
DR7 & 4 & 8.5 & 1 & 2.1 & $4.279(0.460-39.811)$ & 0.181 \\
DR9 & 2 & 4.3 & 5 & 10.6 & $0.373(0.069-2.029)$ & 0.217 \\
DR12 & 25 & 53.2 & 28 & 59.6 & $0.771(0.341-1.746)$ & 0.339 \\
DR13 & - & - & 1 & 2.1 & - & 0.500 \\
DR14 & 2 & 4.3 & 5 & 10.6 & $0.373(0.069-2.029)$ & 0.217 \\
DR15 & 28 & 59.6 & 28 & 59.6 & $1.000(0.439-2.279)$ & 0.583 \\
DR16 & 3 & 6.4 & 6 & 12.8 & $0.466(0.109-1.986)$ & 0.243 \\
DR17 & - & - & 1 & 2.1 & - & 0.500 \\
DR70 & 1 & 2.1 & 1 & 2.1 & $1.000(0.061-16.474)$ & 0.753 \\
\hline
\end{tabular}

TABle 3. Frequency of HLA-DR aleLE on Steroid SENSitive PATIENTS AND CONTROLS

\begin{tabular}{lcccccc}
\hline Allele & \multicolumn{2}{c}{ Cases } & \multicolumn{2}{c}{ Control } & OR (95\%Cl) & P \\
& $\mathbf{n}(\mathbf{3 0})$ & $\%$ & $\mathbf{n}(\mathbf{4 7})$ & $\%$ & & \\
DR1 & 4 & 13.3 & 2 & 4.3 & $3.462(0.593-20.215)$ & 0.147 \\
DR3 & 2 & 6.7 & - & - & - & 0.072 \\
DR4 & 12 & 40.0 & 1 & 1.1 & $30.667(3.712-263.330)$ & 0.0002 \\
DR7 & 2 & 6.7 & 1 & 2.1 & $3.286(0.285-37.924)$ & 0.315 \\
DR9 & 1 & 3.3 & 5 & 10.5 & $0.290(0.032-2.610)$ & 0.243 \\
DR12 & 18 & 60.0 & 29 & 59.36 & $1.018(0.400-2.591)$ & 0.970 \\
DR13 & - & - & 1 & 2.1 & - & 0.554 \\
DR14 & 2 & 2.7 & 5 & 10.6 & $0.600(0.109-3.311)$ & 0.554 \\
DR15 & 17 & 56.7 & 29 & 6.2 & $0.887(0.351-2.244)$ & 0.801 \\
DR16 & 1 & 3.3 & 6 & 12.8 & $0.235(0.87-2.063)$ & 0.160 \\
DR17 & - & - & 1 & 2.1 & - & 0.421 \\
DR70 & 1 & 3.3 & 1 & 2.1 & $0.586(0.095-26.360)$ & 0.745 \\
\hline
\end{tabular}


MP Damanik: HLA-B60 and HLA-DR4 in children with steroid-sensitive nephrotic syndrome

\section{Discussion}

Our study showed the association between HLA-B60 and PNS. Other study has also reported weak association between PNS and other HLA Class I i.e, HLA-A3 and HLA-A2. ${ }^{9}$ These results could be due to the individual immunogenetic characteristics of different populations. The significant association between HLA-B60 allele and PNS confirmed its role as the risk factor of PNS among children. The stronger association of HLA-B60 allele and PNS compared to normal population in Indonesia proved the role of T-cell, particularly $\mathrm{CD}^{+}$, in the pathogenesis of PNS in children. ${ }^{10}$ In PNS, HLA-B60 plays a role in the exposure of $\mathrm{CD}^{+}{ }^{+} \mathrm{T}$-cell, as well as in the regulation of cytokine release which influence the basal membrane of glomeruli and later causes severe proteinuria. This study also showed very significant association between HLA-DR4 and PNS in children. This result confirmed the results of other studies done on other population. The results from this study support the hypothesis that HLA-DR4 as genetic marker of the PNS. Immunogenetic factor plays an important role in the development of PNS, and this is shown by the association between PNS and HLA-DR4, and CD4 is the T-cell lymphocyte population that plays role in the pathogenesis of PNS by the regulation of cytokine release to influence basal membrane of glomerulus and causes proteinuria. A metaanalysis showed that HLA-DR4 is the universal marker of PNS, as has been shown in this study. Other studies conducted on different population showed the association of PNS with types of HLA-DR, such as the HLA-DR8; ${ }^{11}$ HLA-DR3, DR7, and DR8;12 HLA-DR7 and DR9; ${ }^{13}$ and HLA-DR7. ${ }^{14}$ For the association between HLA-DR4 and PNS with steroid sensitive, the result of this study showed that there was association between HLA and PNS with SSNS in children.

In conclusion, the close association between PNS and HLA antigen gives further support to an immunogenetic background of the disease which seems to be stronger in young children with SSNS.

\section{References}

1. Taube D, Williams DG. Pathogenesis of minimal change nephropathy. In: Comeron JS, Glassock, RJ, editors. The nephrotic syndrome. Dekker, New York; 1988. p. 163-93.

2. Thomson G. HLA disease association: Models for the study of complex human genetic disorders. Crit rev Clin Lab Sci 1995;32:183-219.

3. Thomson PD, Barratt TM, Stokes CR, Turner MW, Soothill JF. HLA antigen and atopic feature in steroid-responsive nephrotic syndrome of childhood. Lancet 1976;9:765-8.

4. Hoeffner A, Abbal M, Mytilineos J, Konrad M, Kramer I, Bouissou F, et al. Oligotyping for HLA-DQA, -DQB, and -DPB in idiopathic nephrotic syndrome. Pediatric Nephrol 1997;11:291-5.

5. De Mouzon-Cambon A, Bouisssou F, Dutau G, Barthe P, Parra MT, Sevin A, et al. HLA-DR7 in children with idiopathic nephrotic syndrome. Correlation with atopy. Tissue antigens 1981;17:518-24.

6. Bouissou F, Meissner I, Konrad M, Somner E, Mytilineos J, Ohayon E, et al. Clinical implications from studies of HLA antigens in idiopathic nephrotic syndrome in children. Clin Nephrol 1995;44:279-83.

7. Konrad M, Mytilineos J, Ruder H, Opelz G, Scharer K. HLA-DR7 predicts the response to alkylating agents in steroid-sensitive nephrotic syndrome. Pediatr Nephrol 1997;11:16-9.

8. Zhou GP, Guo YQ, Ji YH, Zhang GL Major histocompasibility complex class II antigens in steroid-sensitive nephrotic syndrome in Chinese children. Pediatr Nephrol 1994;8:140-1.

9. Mir S, Kutukculer N, Kavakli K. Major histocompatibility complex antigens in Turkish children with steroid-responsive nephrotic syndrome. Pediatr Nephrol 1994;8:259-60.

10. Damanik MP, Hardyanto S, Gotoh A. Human leucocyte antigens in primary nephrotic syndrome on Indonesian children. KONAS V PERALMUNI, 24-26 Maret 2005, Yogyakarta.

11. Ruder H, Scharer K, Lenhard V, Wingen AM, Opelz G. HLA phenotypes and idiopahtic nephrotic syndrome in children. Proc Eur Dial Transpl Assoc 1983;19: 602-6.

12. Zaki M, Daoud AS, Al Saleh QA, Al Najedi AK, White AG. HLA antigens in Arab children with steroid-responsive nephrotic syndrome. Pediatr Nephrol 1994;8:74-5.

13. Konrad M, Mytilineos J, Bouissou F, Scherer S, Gulli MP, Meissner J, et al. HLA- class II association with idiopathic nephrotic syndrome in children. Tissue antigen 1994;43:275-80.

14. Al-Eisa AA, Haider M, Srivasta BS. HLA-DRB11 alleles in Kuwaiti children with idiopathic nephritic syndrome. Pediatr Nephrol 2000;15:79-81. 